\title{
Sintering Study of Polyamide 12 Particles for Selective Laser Melting
}

\author{
http://dx.doi.org/10.3991/ijes.v3i1.4290 \\ M. Zhao, D. Drummer, K. Wudy and M. Drexler \\ Friedrich-Alexander-Universität Erlangen-Nürnberg, Erlangen, Germany
}

\begin{abstract}
Selective Laser Melting is an additive manufacturing technique, using a laser to promote the fusion followed by the solidification of a powder bed into a component. One of the most interesting topics about this process is the coalescence behavior of particles taking place in the powder bed during exposure. The coalescence of particles has been investigated in different fields of materials. Polyamide 12 (PA12) is a polymer material which is usually used in the selective laser melting process. Therefore, the characterization of the sintering behavior of PA12 powder plays an important role to improve the performance of the material and the process.
\end{abstract}

The purpose of this study is to investigate the sintering process of PA12. The main goals are: to calculate the neck growth during isothermal sintering process based on the modified Frenkel's model; and to compare the sintering model with results from microscopic observation of PA12 powder in the hot stage. Important parameters for the sintering model such as temperature-sensitive viscosity and surface tension are measured in this paper. Furthermore, the effects of heating rate and sintering temperature on the neck growth were investigated by the microscopic observation of molten particles in the hot stage. The modeling showed a reasonable agreement with the microscopic observation in the hot stage. Specially, the effect of the heating rate on the sintering temperature was studied. It was confirmed that the sintering behavior of PA12 powder started at a higher temperature with increasing heating rate. Based on the findings from this study, a preliminary methodology for PA12 powder sintering is proposed. It provides a better understanding of the properties of the material, and more efficient use of the selective laser melting material.

Index Terms-coalescence, hot stage microscopy, sintering behavior, selective laser melting.

\section{INTRODUCTION}

Selective laser melting of polymeric materials is one of several processes included in the additive manufacturing technologies. It can be employed to generate threedimensional components quickly and with various materials. An outstanding advantage compared with other additive manufacturing techniques such as Fused Deposition Modeling (FDM) and Stereolithography (SLA) is that the material is directly and completely melted by laser irradiation without any complicated post processing steps [1]. In selective laser melting polymer powder layers are heated in certain areas selectively and sintered under the action of a laser beam. Thus, the geometry is created layer by layer through lowering the work platform and applying powder repeatedly [2]. Thermoplastic polymers are converted primarily by means of $\mathrm{CO}_{2}$ laser into the molten state.

The quasi-isothermal laser sintering describes a modelbased access approach that the construction process, where the polymer is available with melt and powder at the same time at the building temperature [3]. For this reason a minimum temperature range for the melting range is desirable, i.e., the polymer should be fully melted upon reaching a temperature limit. The temperature interval between the melting and crystallization temperature should be as large as possible [2]. However, polyamide 12 is mostly offered because of its hydrophilic properties and further due to the big process window which offered to achieve reproducible manufacturing [3].

During the selective laser melting process, there is no pressure as in other plastics manufacturing process (injection molding, extrusion etc.) and the particles are fused to each other. Therefore, sintering kinetics play an important role to understand the melt behavior and movement. Hardly any specific sintering models of plastics for the selective laser melting are available. Sintering is a technical terminology of the consolidation and compaction of powder into a compact due to temperature treatment [4]. The geometric observation of a two-particle model provides the relevant parameters and allows a simplistic description of the sintering. This paper deals with the sintering behavior of two equal-sized particle sintering model for selective laser sintering.

The contour of two spheres of a sintering process is schematically presented in Fig. 1 . The particle radius $a_{0}$ is estimated from the measurements of the projected area of the particles. The angle of the intersection and the radius of the neck are denoted by $\theta(\mathrm{t})$ and $\mathrm{x}(\mathrm{t})$, separately. This increases the radius a on the both spherical elements, until the complete coalescence is achieved in a larger sphere of radius $\mathrm{a}_{\mathrm{f}}=\sqrt[3]{2} \mathrm{a}_{0}[5]$.
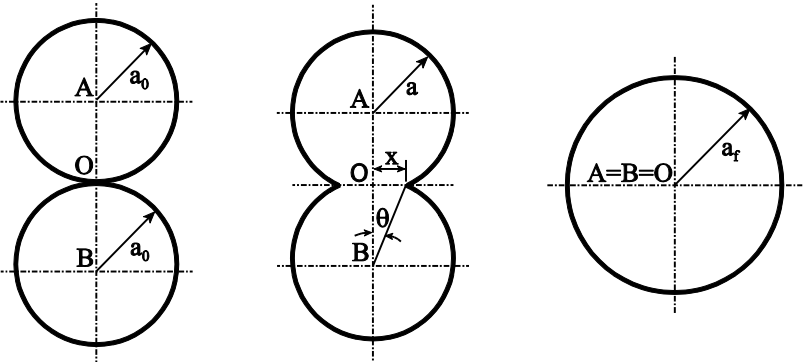

Figure 1. Schematic geometry of two particles during sintering 
It is widely accepted to divide the overall sintering process in three sequential stages. In general, these stages are not discrete, and usually, there is a considerable overlap between two consecutives ones. These stages are defined according to the morphology of the grains and the porosity [6].

a. First stage (formation of the sintering neck): necks are forming and growing between particles. At the end of this stage, the contact area increases by up to $20 \%$ with only a small densification (interparticle penetration). The grain boundaries between the particles remain in the contact plane due to the tensile stresses resulting from the surface tension.

b. Second stage: continuous network of pore channels along the grain edges. During this stage, the pore channel shrinks and grains grow. Most of the densification, and also the growth in the contact area, occur during this stage.

c. Third stage (densification): The pore channels continue to shrink until they pinch off and form isolated spheroidized pores. In this stage, the pore volume fraction asymptotically approaches zero. In some cases, these closed pores may trap gases, making their elimination difficult [6].

Sintering occurs by diffusional transport of matter alone definite paths that define the mechanisms of sintering. The six common material transport mechanisms are:
a. Viscous flow
b. Surface diffusion
c. Volume diffusion
d. Grain-boundary diffusion
e. Evaporation and condensation
f. Melt adhesion [5, 6]

Due to high molecular weight there is no evaporation and diffusion in the case of polymer sintering. There is no significant compression with the polymer particle, whereby the crystal structure can be obtained eliminating it is generally accepted that a viscous flow is the dominant mechanism in polymer. First analytical model for the sintering of two spherical particles was derived by Frenkel [7] in 1945. It describes the rate of coalescence occurring by viscous flow, which is shown below, where $t$ is the sintering time, $a_{0}$ is the particle radius, $\gamma$ is the surface tension and $\eta$ is the viscosity $[5,6,8]$. Knowledge of the function of viscosity and temperature is everywhere of great interest, where the rheological properties of substances to be considered in a wide variety of temperatures. Another temperature-dependent characteristic is the surface tension.

$$
\theta(\mathrm{t})=\left(\frac{\mathrm{t} \cdot \gamma}{\mathrm{a}_{0} \cdot \eta}\right)^{1 / 2}
$$

There are some limitations of the Frenkel's model. Such as the Newtonian flow behavior, no consideration of the particle weight, constant spherical radius and small angle nutrition. Therefore, Frenkel's model describes just the early step of a sintering process. In 1997, a modifica- tion of Frenkel's model has been proposed by Pokluda et al. [9] to predict the complete coalescence of two spheres with an assumption: constant strain rate on the particle geometry [10].

$$
\frac{\mathrm{d} \theta}{\mathrm{dt}}=\frac{\gamma}{\mathrm{a}_{0} \cdot \eta} \cdot \frac{2^{-5 / 3} \cdot \cos \theta \cdot \sin \theta \cdot(2-\cos \theta)^{1 / 3}}{(1-\cos \theta) \cdot(1+\cos \theta)^{1 / 3}}
$$

Fig. 2 shows the sintering kinetic estimations for the Frenkel's and modified Frenkel's models [9]. On the $\mathrm{x}$ axis is specified the dimensionless sintering time $\mathrm{t} \cdot \gamma /\left(\mathrm{a}_{0} \cdot \eta\right)$, which does not consider the material characteristic values. On the $y$ axis is applied the dimensionless neck radius x/a. Because of the limitations the Frenkel's model could describe the early sintering stage, where the curve runs indefinitely. Numerical results from a classical Runge-Kutta-Fehlberg method of the present modified Frenkel's model are presented. The initial condition was set at the value for dimensionless time $t \cdot \gamma /\left(a_{0} \cdot \eta\right)=0.0001$ instead of zero and from Eq.(1) $\theta_{0}=0.01$. Particularly, when the dimensionless neck radius in the graph becomes 1.0 , the coalescence of the particles is completed. For this reason, the modified Frenkel's model will be chosen [9]. Experiments were conducted in $[11,12]$ using pairs of particles inside a hot stage microscopy setup with the ultimate objective to study the coalescence, which is a crucial stage in the rational molding process.

As in the paper by Pokluda et al. described, that only the dimensionless sintering time has been studied. And in this dimensionless parameter are included four variants: sintering time $\mathrm{t}$, temperature-sensible viscosity $\eta$, surface tension $\gamma$, as well as the particle radius a0, which vary in the selective laser melting investigations. The temperature-sensible parameters were measured as described in chapter 2 in order to continue the modeling. Otherwise, an efficient experimental method was examined. The main goals are: to calculate the neck growth during isothermal sintering process based on the modified Frenkel's model; and to compare the sintering model with the real sintering behavior results from microscopic observation of PA12 powder in the hot stage.

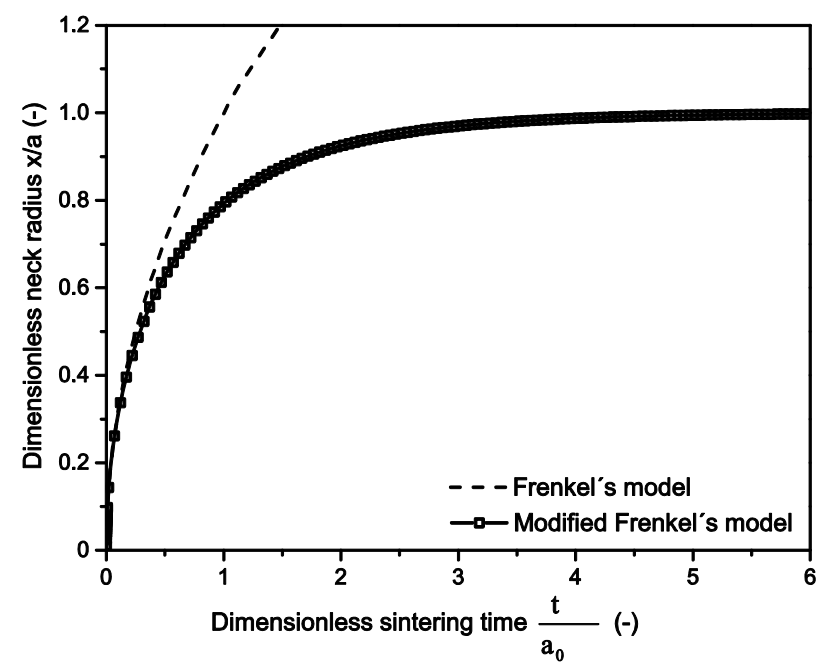

Figure 2. Coalescence curves comparied Frenkel's model with the modified Frenkel's model of Pokluda [9] 


\section{EXPERIMENTAL PROCEDURES}

\section{A. Materials}

The experiments were performed using polyamide 12 (type: PA 2200, supplier: EOS). The particle size analysis was carried out using a particle size analyzer Morphologi $\mathrm{G} 3 \mathrm{~s}$ from Malvern Instruments. The particle diameter volumetrically $\mathrm{d} 50,3$ is $61.4 \mu \mathrm{m}, \mathrm{d} 10,3$ is $45.8 \mu \mathrm{m}$ and $\mathrm{d} 90,3$ is $81.0 \mu \mathrm{m}$. The polyamide 12 powder used in further studies would first start with the d50,3 particle, i.e. the particle size about $61.4 \mu \mathrm{m}$. For the implementation of the differential scanning calorimetry DSC Q1000 from TA Instruments was used. The melting peak temperature is $185^{\circ} \mathrm{C}$ with a heating rate of $10 \mathrm{~K} / \mathrm{min}$.

\section{B. Rheological properties}

As the sintering of polymers is influenced by the viscosity, it is important to determine an appropriate method to measure the temperature-dependent viscosity. Polymers are viscoelastic materials, which mean they are able to show two types of deformation: reversible deformation for the elastically behavior, irreversible deformation for viscose behavior [13].

Subsequently, the rotational rheometer was used to obtain the viscosity with zero shear rates. To achieve this information, it was necessary to take the flow data from the low shear region and select an appropriate flow model to compute the data $[14,15]$.

Small amplitude oscillatory shear tests were carried out on a stress-controlled rotational rheometer AR2000 from TA Instruments with plate-plate geometry (diameter $25 \mathrm{~mm}$, frequency $0.1 \mathrm{~Hz}$, deformation $0.05 \%$ ). All rheological measurements were carried out in the linear viscoelastic regime as was verified by preliminary strain sweep tests. The viscosity of the melt was measured at $200^{\circ} \mathrm{C}$, $205^{\circ} \mathrm{C}, 210^{\circ} \mathrm{C}, 215^{\circ} \mathrm{C}$ and $220^{\circ} \mathrm{C}$. One of the difficulties was that, polyamide 12 chain length increases due to its post condensation at a high temperature, which results in higher melt viscosity. Therefore, the viscosity measurement is a multi-scale measurement that, the strong interactions have all parameters (frequency, temperature, time etc.) of each other.

\section{Surface tension measurements}

Advanced knowledge of the surface properties of powder and melted polymers were required for the modeling of the material properties. In fact, these properties affect directly the consolidation, the wetting behavior, the contour accuracy, shape details and surface roughness [2, 15].

The experiments to measure the interfacial effect were performed using image-based droplet over a punch geometry. The Surface tension of the plastic melts were measured at $200{ }^{\circ} \mathrm{C}, 205^{\circ} \mathrm{C}, 210^{\circ} \mathrm{C}, 215^{\circ} \mathrm{C}$ and $220^{\circ} \mathrm{C}$ with Punch method in a heated cell and argon atmosphere [16].

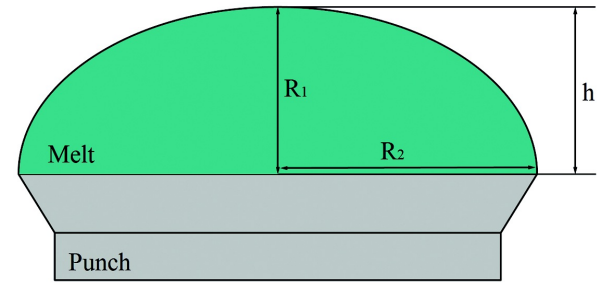

Figure 3. Schematically surface tension measurement using Punch method
The surface tension $\gamma$ was calculated by using YoungLaplace equation, where $\rho$ is density of melt, $\mathrm{g}$ is gravity and $\gamma$ is melt surface tension [11]. The equation describes the difference between the pressure above and below the curved elements of a liquid/solid interface.

$$
\gamma \cdot\left(\frac{1}{R_{1}}+\frac{1}{R_{2}}\right)=\rho \cdot g \cdot h
$$

\section{Hot stage microscopy}

Microscopic observations for sintering of polymer particles have been performed using a Linkam FTIR600 heating and freezing microscope stages, controlled with central processor Linksys 32 software. The sample, which consisting of two polyamide 12 particles of approximately equal size, was placed on the stage at ambient temperature. A glass slide was used as substrate for the sintering particles. The temperature was then set to the sintering conditions with different heating rates between $1{ }^{\circ} \mathrm{C} / \mathrm{min}$ $150{ }^{\circ} \mathrm{C} / \mathrm{min}$. The modified Frenkel's model describes an isothermal sintering process. To perform the comparable experimental investigations, the sintering by hot stage microscopy would be also isothermal [17].

\section{RESUltS AND DisCUSSIONS}

\section{A. Modified Frenkel's model}

It is essential to conduct measurements on the temperature-sensible viscosity and surface tension to derive a sintering model. Table I presents the nomenclature of the various samples with their temperature-sensitive viscosities and surface tensions measured between $200{ }^{\circ} \mathrm{C}$ and $220^{\circ} \mathrm{C}$. It can be claimed that, with increasing temperature, the surface tension and the viscosity are lowered continuously. However, the viscosity is more temperature dependent.

TABLE I.

VISCOSITY AND SURFACE TENSION MEASURES AT DIFFERENT TEMPERATURES, THREE TIMES WITH AVERAGE AND STANDARD DEVIATION

\begin{tabular}{|c|c|c|}
\hline $\begin{array}{c}\text { Temperature } \\
\left({ }^{\circ} \mathbf{C}\right)\end{array}$ & $\begin{array}{c}\text { Viscosity } \\
\boldsymbol{\eta} \\
(\mathbf{P a} \cdot \mathbf{s})\end{array}$ & $\begin{array}{c}\text { Surface Tension } \\
\boldsymbol{\gamma} \\
(\mathbf{m N} / \mathbf{m})\end{array}$ \\
\hline 200 & $2616 \pm 99$ & $36.3 \pm 1.7$ \\
\hline 205 & $2368 \pm 131$ & $35.7 \pm 0.8$ \\
\hline 210 & $2133 \pm 128$ & $35.6 \pm 1.1$ \\
\hline 215 & $1933 \pm 65$ & $35.0 \pm 1.2$ \\
\hline 220 & $1778 \pm 39$ & $34.5 \pm 1.0$ \\
\hline
\end{tabular}

Data has been analyzed according to the modified Frenkel's model for coalescence, which can be converted into form in (4). The function $\mathrm{d} \theta / \mathrm{dt}$ is proportional to the surface tension and inversely proportional to the particle size and viscosity, where viscosity doesn't decrease linearly.

$$
\frac{\mathrm{d} \theta}{\mathrm{dt}} \sim \frac{\gamma}{\mathrm{a}_{0} \cdot \eta}
$$


PAPER

Sintering Study of Polyamide 12 Particles for Selective Laser Melting

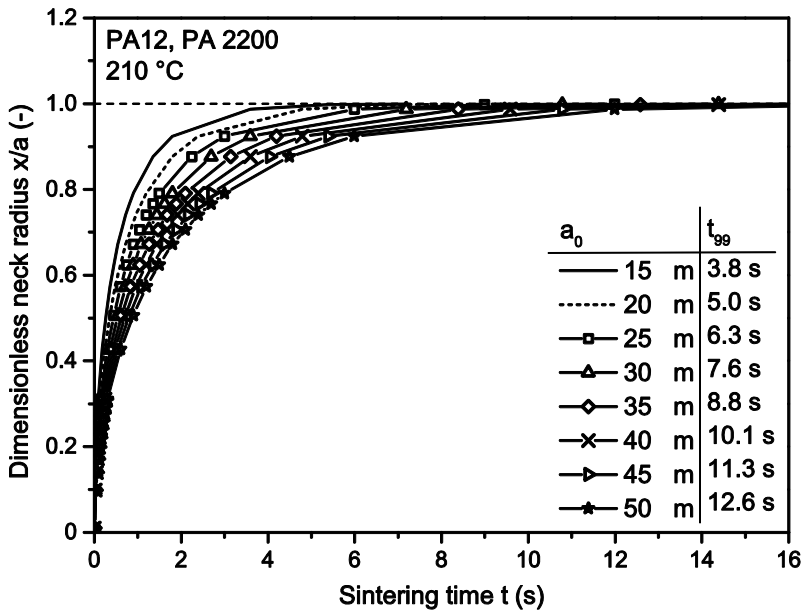

Figure 4. Coalescence curves of modified Frenkel's model of different particle radiuses

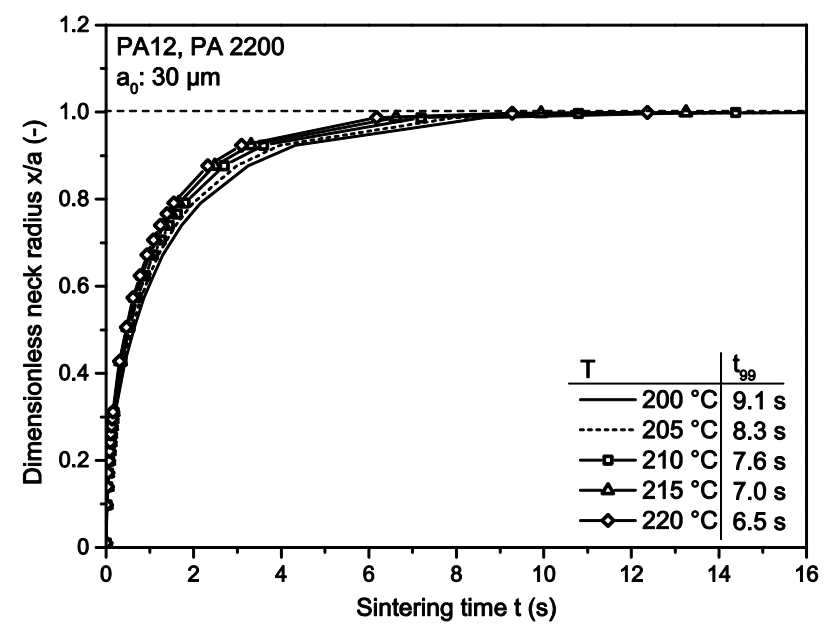

Figure 5. Coalescence curves of modified Frenkel's model at different temperatures

The modified Frenkel's model was presented for the polyamide 12 with different particle radius between $15 \mu \mathrm{m}$ and $50 \mu \mathrm{m}$ at $210^{\circ} \mathrm{C}$ in Fig. 4 . In this figure $\mathrm{x}$-axis represents sintering time replaced with the dimensionless sintering time.

The sintering time $t_{99}$, at which $99 \%$ of the sintering neck growth is finished, takes for two particles with $15 \mu \mathrm{m}$ radius $3.8 \mathrm{~s}$. The particles with $50 \mu \mathrm{m}$ radius take then $12.6 \mathrm{~s}$. The sintering time at the same temperature is in proportion to the particle radius.

The growth of the dimensionless neck radius at the temperature between $200{ }^{\circ} \mathrm{C}$ and $220{ }^{\circ} \mathrm{C}$ for the polyamide 12 with particle radius $30 \mu \mathrm{m}$ is shown in Fig. 5. A tendency is that, with increasing temperature, the particle neck growth is faster. As has been shown in Fig. 5, the change of sintering time $t_{99}$ decreases with increasing temperature. For example, the $t_{99}$ shortened 0.8 second from $200{ }^{\circ} \mathrm{C}$ to $205^{\circ} \mathrm{C}$, while the change of $t_{99}$ between $215^{\circ} \mathrm{C}$ and $220^{\circ} \mathrm{C}$ is 0.5 second. After the trend can be assumed, if the temperature continues to increase, the shortening of the sintering time is not as significant as in the low temperature range.

\section{B. Experimental determination of the sintering progress}

Fig. 6 presents a sintering sequence for polyamide 12 powder particles by hot stage microscopy. An evaluation
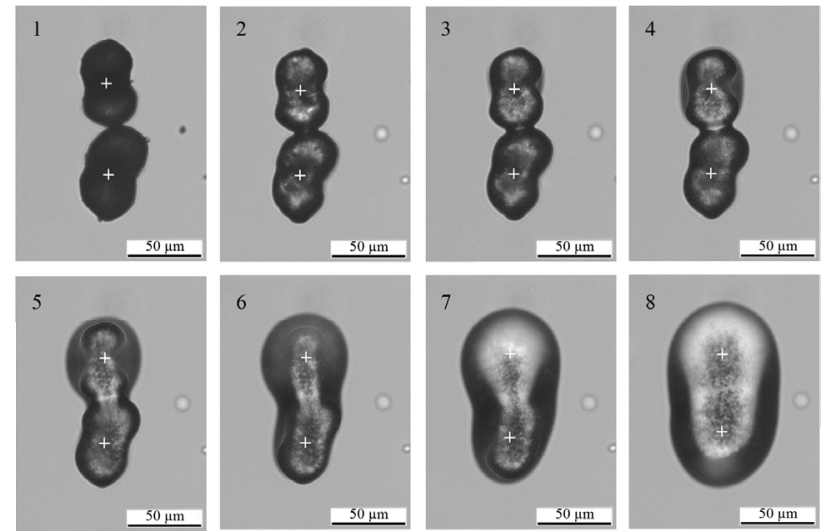

Figure 6. Two polyamide 12 (PA 2200) particles sintering by hot stage microscopy by a heating rate of $70{ }^{\circ} \mathrm{C} / \mathrm{min}$ at different temperatures
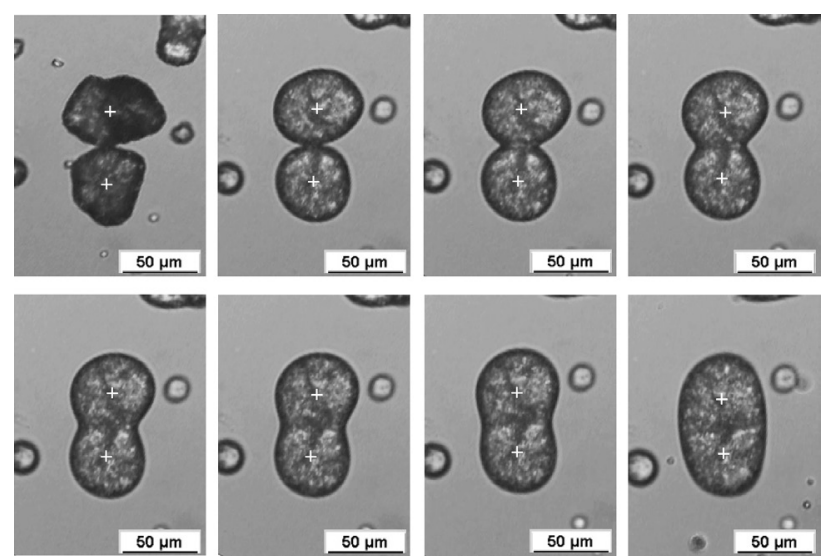

Figure 7. Two polyamide 12 (PA 2200) particles isothermal sintering by hot stage microscopy with silicone oil by a heating rate of $150{ }^{\circ} \mathrm{C} / \mathrm{min}$ at $195^{\circ} \mathrm{C}$

of the particle radius was assumed, that the radius of the projection converts back to the radius. The sintering neck was easily recognized. Firstly, the test was conducted at a heating rate of $70{ }^{\circ} \mathrm{C} / \mathrm{min}$. In this case the heating was not homogeneous. On one hand, the upper particle has first melted gradually from picture 1 to 5 . From picture 6 , the lower particle has begun to melt, because the hot stage was heated only from below. On the other hand, the particles were adhered to the glass slide. The small white cross describes the center point of each particle. The positions did not change. In Fig. 6, the sintering particle size was more than two-times bigger than the start particle size.

Fig. 7 presents the sintering of polyamide 12 by hot stage microscopy with silicone oil film. To minimize the liability, the high-viscosity silicon oil was used. A drop of silicone oil on the glass slide was first heated up to $300^{\circ} \mathrm{C}$ and held for at least 3 minutes. These would lead to a thin film of the silicone oil. Then the particles are put on the film. By using the silicone oil, the adhesion between the particle and the glass plate was reduced and heat conduction was improved.

For the analysis the particle radius was taken from the average of the two particles. The sintering neck radius was half of the narrowest position as shown in Fig. 1 schematic geometry.

The increases of the melt peak temperature with increasing heating rate for high-density polyethylene (HDPE) and poly(aryl ether ether ketone ketone) (PEEKK) have been studied in $[18,19]$ with the help of 
the typical measurements of the differential scanning calorimetry (DSC) at different rates. Before the isothermal measurements, the non-isothermal conditions have to be measured to find the first sintering neck occur at different heating rates in different time points. The time and temperature were recorded, thus to perform accurate isothermal measurements at different heating rates. Fig. 8 shows the coalescence temperature is dependent on the hating rate. With increasing heating rate, the coalescence temperature increases. With increasing heating rate the plastic particles would be melted at higher temperature. The highest heating rate of the used hot stage was $150{ }^{\circ} \mathrm{C} / \mathrm{min}$, which reached a melting temperature at $195^{\circ} \mathrm{C}$. In the process the powder is heated with a laser, and the laser heating rate for polyamide 12 is substantially higher than $150{ }^{\circ} \mathrm{C} / \mathrm{min}$. Therefore, if an isothermal sintering process at higher temperature would be investigated, the heating rate would be further increased.

The experimental results of sintering dimensionless neck growth for PA12 at temperatures of $192{ }^{\circ} \mathrm{C}$ and $195{ }^{\circ} \mathrm{C}$ are plotted in Fig. 9. The sintering neck growth curve at $192^{\circ} \mathrm{C}$ increases continuously throughout the sintering process. The sintering curve at $195^{\circ} \mathrm{C}$ shows an agreeable trend, that the curve increases firstly very quickly and after that slows down. If the temperature decreases, the increases in the first and second stages are also slower. The explanation is that, the viscosity at low temperature is small. Therefore, the flow ability is not as good at higher temperatures. According to this tendency, they are approximately the same courses as the model with increasing temperature. It can be concluded that there are more influencing factors of the temperature in experiments of the hot stage microscopy.

\section{Sintering modeling vs. Sintering by hot stage microscopy}

An improvement on the result shown above can be made based on the data provided. Results of experimental applications of this sintering analysis in Fig. 10 procedure are given to illustrate the proposed technique. Good agreement is observed between experimental melting behavior of polyamide 12 and model prediction according to (2) is shown, when a thermal and physical history is applied. Both experimental and model curves are obtained

using the following physical and thermal history: 1) particle size a0 ca. $30 \mu \mathrm{m} ; 2$ ) isothermal step at $195^{\circ} \mathrm{C}$, where melting has begun, but not yet completed. The curve of the experiment was different from the curve of the modeling. Because the decrease in surface free energy is divided into two parts, one is for the sintering, and the other is for the rough surface.

\section{CONCLUSIONS}

This paper presented a theoretical and experimental study of the sintering process of commercial polyamide 12 powders for selective laser melting. The modified Frenkel's model has given an explanation of the sintering neck growth is dependent on sintering time, viscosity, surface tension and particle radius of the powder. Viscosity is a determining factor for the modeling of the temperature. The influence of particle radius has a lot greater than the temperature. In conclusion, sintering time increases with increasing of particle radius and decreasing of temperature. The results of hot stage microscopy have shown that, the sintering neck growth at $195^{\circ} \mathrm{C}$ has agreed with the modeling.

There is some further research for a better understanding of sintering neck growth for polyamide 12, such as: regarding the effects of the particle diameter, particle shape and further height temperature. The corrections between the modified Frenkel's model and the real investigations have to be found. And the new sintering model for commercial selective laser melting powder is used to develop the new materials and to optimize the process.

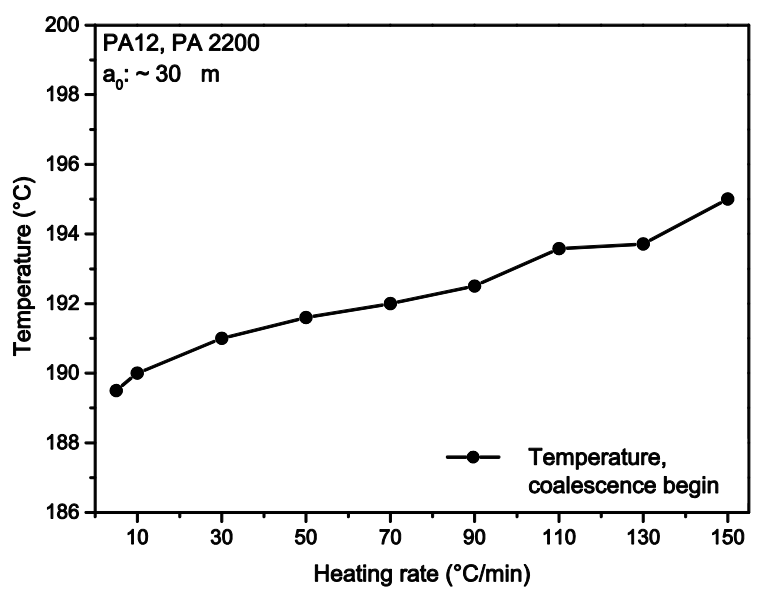

Figure 8. Coalescence temperature is dependent on the heating rate by hot stage microscopy

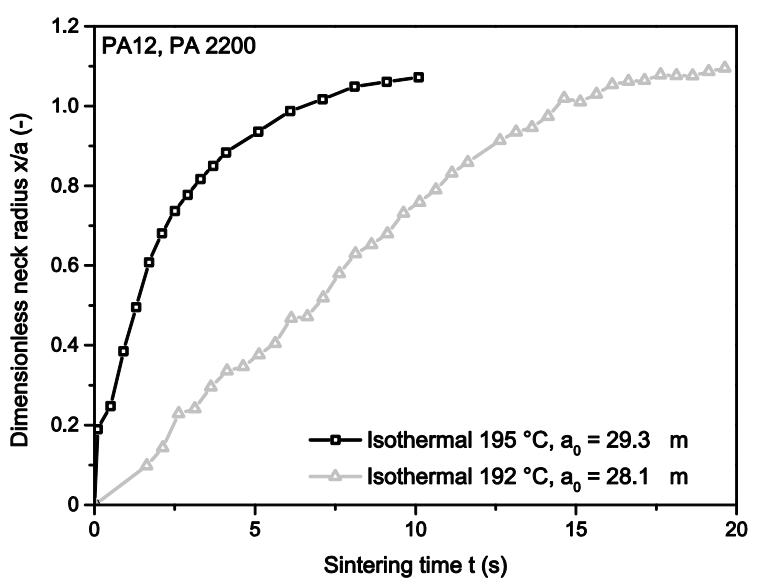

Figure 9. Sintering dimensionless neck growth for polyamide 12 powder particles at different temperatures

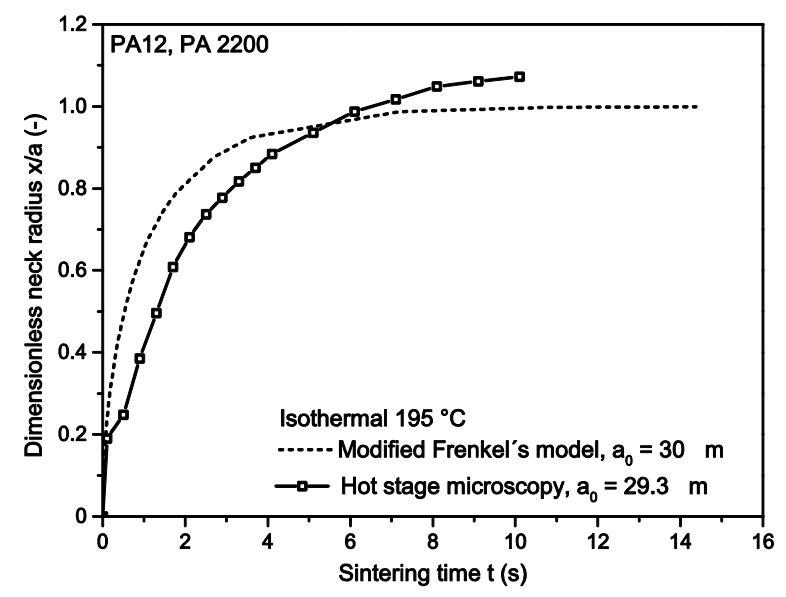

Figure 10. Sintering modeling vs. Sintering by hot stage microscopy 
PAPER

\section{Sintering Study of Polyamide 12 Particles for Selective Laser Melting}

\section{ACKNOWLEDGMENT}

The authors want to thank the German Research Foundation (DFG) for funding the Collaborative Research Center 814 (CRC 814), sub-project A03.

\section{REFERENCES}

[1] D.T. Pham and R.S. Gault, "A comparison of rapid prototyping technologies", International Journal of Machine Tools \& Manufacture, vol. 38, pp. 1257-1287, 1998. http://dx.doi.org/10.1016/ S0890-6955(97)00137-5

[2] T. Seul, "Approaches to material's optimization in laser sintering with characterization and modification of surface-energy phenomena”, „Ansätze zur Werkstoffoptimierung beim Lasersintern durch Charakterisierung und Modifizierung grenzflächenenergetischer Phänomene", Dissertation, Aachen, 2004.

[3] A. Gebhardt, "Understanding Additive Manufacturing", Carl Hanser Verlag, 2012.

[4] G. Menges, R. Schulze-Kadelbach, H. Reichstein, U. Thebing and J. Schmitz, "Study of the bases for the sintering of platics”, „Untersuchung der Grundlagen für das Sintern von Kunststoffen“, Rheologica Acta, vol. 19, pp. 633-641, 1980. http://dx.doi.org/10.1007/BF01517517

[5] M. Kirchhof, "Sintering kinetics of nanoscale particles”, ,Sinterkinetik nanoskaliger Partikel", Dissertation, Erlangen, 2008.

[6] R.F. Walker, "Mechanism of Materials Transport during Sintering", Journal of the American Ceramic Society, vol. 38, pp. 187197, 1955. http://dx.doi.org/10.1111/j.1151-2916.1955.tb14928.x

[7] J. Frenkel, "Viscous Flow of Crystalline Bodies under the Action of Surface Tension", Journal of Phyiscs, vol. 9, pp. 385-391, 1945.

[8] J.D. Muller and A. Maazouz, "Sintering of Two Drops of Model Fluids", International Journal of Material Forming, vol. 1, pp. 645-648, 2008. http://dx.doi.org/10.1007/s12289-008-0338-z

[9] O. Pokluda, C.T. Bellehumeur and J. Vlachopoulos, "Modification of Frenkel's model for sintering", AIChE Journal, vol. 43, pp. 3253-3256, 1997. http://dx.doi.org/10.1002/aic.690431213

[10] C.T. Bellehumeur, M. Kontopoulou and J. Vlachopulos, "The role of viscoelasticity in polymer sintering", Rheologica Acta, vol. 37, pp. 270-278, 1998. http://dx.doi.org/10.1007/s003970050114

[11] C.T. Bellehumeur, M.K. Bisaria and J. Vlachopoulos, "An experimental study and model assessment of polymer sintering", Polymer Engineering \& Science, vol. 36, pp. 2198-2207, 1996. http://dx.doi.org/10.1002/pen.10617

[12] M. Asgarpour, F. Bakir, S. Khelladi, A. Khavandi and A. Tcharkhtchi, "Characterization and modeling of sintering of polymer particles", Journal of Applied Polymer Science, vol. 119, pp. 2784-2792, 2011. http://dx.doi.org/10.1002/app.32924
[13] W.M. Kulicke and C. Clasen, "Viscosimetry of Polymers and Polyelectrolytes", Springer, 2004. http://dx.doi.org/10.1007/978-3662-10796-6

[14] J. W. Gooch, "Encyclopedic Dictionary of Polymers", Springer, pp. 943-944, 19889.

[15] B. Haworth, N. Hopkinsion, D. Hitt and X. Zhong "Shear viscosity measurements on polyamide- 12 polymers for laser sintering", Rapid Prototyping Journal, vol. 19, pp. 30-32, 1995.

[16] K. Wudy, D. Drummer and M. Drexler, "Characterization of polymer materials and powders for selective laser melting", Proceedings of the Polymer Processing Society 30th Annual Meeting (PPS), Nuremberg, 2014.

[17] A. Kopczynska, "Surface tension phenomena in plastics determination and application”, „Oberflächenspannungsphänomene bei Kunststoffen - Bestimmung und Anwendung", Dissertation, Erlangen, 2008.

[18] A. Greco and A. Maffezzoli, "Polymer melting and polymer powder sintering by thermal analysis", Journal of Thermal Analysis and Calorimetry, vol. 72, pp. 1167-1174, 2003. http://dx.doi.org/10.1023/A:1025096432699

[19] T. Liu, Z. Mo, S. Wang and H. Zhang, "Nonisothermal melt and cold crystallization kinetics of poly(aryl ether ether ketone ketone", Polymer Engineering \& Science, vol. 37, pp. 568-575, 1997. http://dx.doi.org/10.1002/pen. 11700

\section{AUTHORS}

M. Zhao is with the Institute of Polymer Technology, Friedrich-Alexander-Universität Erlangen-Nürnberg, Erlangen, 91058 Germany (e-mail: zhao@ lkt.unierlangen.de).

D. Drummer is head of the Institute of Polymer Technology, Friedrich-Alexander-Universität ErlangenNürnberg, Erlangen, 91058 Germany (e-mail: info@lkt.uni-erlangen.de).

K. Wudy is with the Institute of Polymer Technology, Friedrich-Alexander-Universität Erlangen-Nürnberg, Erlangen, 91058 Germany (e-mail: wudy@ 1kt.unierlangen.de).

M. Drexler is with the Institute of Polymer Technology, Friedrich-Alexander-Universität Erlangen-Nürnberg, Erlangen, 91058 Germany (e-mail: wudy@ 1kt.unierlangen.de).

This work was supported in part by German Research Foundation (DFG) for funding the Collaborative Research Center 814 (CRC 814), subproject A03. Itis an extended and modified version of a paper presented at the International Conference on Additive Technologies (ICAT2014), held from 15-17 October 2014 in Vienna, Austria. Submitted 28 November 2014. Published as resubmitted by the authors 10 March 2015. 